\title{
SOBRE LA IMPORTANCIA DE LO VERO-SÍMIL y de la imaginación en el mito platónico para la captación del mundo como imagen de las ideas
}

\author{
Fernando Inciarte (1929-2000)
}

\begin{abstract}
Resumen: Este artículo se ocupa de las relaciones del intelecto filosófico con la verdad o las enseñanzas contenidas en la religión positiva. Para ello, centra, en un primer lugar, la atención en algunos textos platónicos en los que Sócrates revela su actitud respecto de lo religioso, especialmente en la Apolo-gía, Cratilo y Fedro. En un segundo momento, a partir de una lectura novedosa de algunos pasajes centrales del Sofista y del Timeo, se busca justificar el carácter autónomo y de auténtico conocimiento de la filosofía, en cuanto explicación de la realidad como imagen de las ideas. Ahí encuentra el autor la auténtica perspectiva desde la que el hombre puede acercarse al conocimiento del mundo y de las cosas divinas.

On the importance of the verosimile and the imagination in the Platonic myth for the capture of the world as an image of ideas
\end{abstract}

Palabras clave: Platón, verosimilitud, imagen, imaginación, mito, religión positiva.

Abstract: This paper engages with the relations of the philosophical intellect with the truth or the teachings contained in a positive religion. In first place, it focuses its attention on some Platonic texts in which Socrates reveals his attitude towards religion, especially in the Apology, Cratylus, and Phaedrus. Secondly, based in a novel reading of some central passages of the Sophist and Timaeus, it seeks to justify the autonomous character and authentic knowledge of philosophy as an explanation of reality as image of ideas. There the author finds the authen- 
tic perspective from which man can approach the knowledge of the world and the divine things.

Keywords: Plato, Verosimilitude, Image, Imagination, Myth, Positive Religion.

Reconstruyámonos el ambiente de la Apología de Sócrates, según Platón, en su tercera fase. Más que de Apología se trata, por tanto, de una despedida. La defensa de Sócrates ha terminado; la votación en contra de éste, también; y, por último, también ha tenido lugar la declaración de la pena de muerte. En este momento, Sócrates se levanta de nuevo, para hablar por última vez. Sus palabras se refieren a la muerte, al sentido de la muerte; hacia el final, resume este sentido: "Si esto significa la muerte", dice, "yo la tengo por ganancia": ei oûn toioûton ho thánatos estin, kérdos égoge légo (40e2). Lo mismo, exactamente lo mismo, que san Pablo dice, con las mismas palabras, sobre la muerte a los de Filipo: "Para mí el vivir es Cristo, kai to apothanein kérdos: y el morir una ganancia (Pbil. 1. 21). Sigue hablando Sócrates de la muerte. Poco antes de terminar su despedida dice, asimismo como resumen de lo anterior, estas palabras: "Ante la muerte nuestra actitud ha de ser de confianza; porque una cosa es cierta: que nada malo puede suceder al hombre bueno ni en la vida ni en la muerte y que los dioses no se desentienden de su suerte" (41c8-12). Lo mismo exactamente escribirá san Pablo más tarde. Pero, estas coincidencias no han sido más que el empujón inicial para las reflexiones que siguen. De lo que en realidad quiero hablar es de algunos aspectos, a mi modo de ver, muy de tener en cuenta, sobre la actitud de Sócrates y de Platón 
ante la religión positiva en general y, naturalmente también, ante las que les tocó en suerte o en desgracia.

Para ir entrando en materia quiero citar otra coincidencia, que demuestra hasta qué punto Sócrates no estaba tan convencido de la bondad natural del hombre como algunos piensan y que llegó incluso a hablar de la condenación de los malos en términos que bien podrían provocar la irritación de todo buen liberal. Refiriéndose, en efecto, a la vida de ultratumba, en lo que él cree poder esperar con fundamento (euelpis), llega en un momento de su discurso a hablar del Tártaro, del Infierno. De él, dice, no saldrán jamás los que hayan cometido los mayores crímenes (Fedón 113e), mientras que los que hayan sido culpables de delitos menos graves podrán abandonarlo después de haber sido purificados. Las coincidencias con la doctrina cristiana se podrían multiplicar, por más que hoy día haya muchos investigadores empeñados en demostrar que la interpretación cristiana de Platón no fue sino un engaño piadoso.

Pero lo más interesante en todo esto es, a mi modo de ver, algo que, a primera vista, pudiera parecer contradictorio. Porque si, después de haber admirado la clarividencia de Sócrates, dijéramos que lo más admirable, a su vez, de todo es que nada de lo dicho lo afirmó Sócrates, o en su caso, Platón como algo seguro, parecería que este segundo motivo de admiración destruiría el primero. Se impone, por tanto, una explicación.

El hecho es que Sócrates, en efecto, cierra toda su disquisición admirable sobre la vida de ultratumba con la observación de que sería impropio de un hombre razonable afirmar que todo eso sea en la realidad exactamente como lo acaba de describir: lo más que conviene a una persona sensata es decir que, 
dado que el alma es inmortal, merece la pena aventurarse (kindineûsai) a pensar que su estado después de la muerte será como lo acaba de describir, "ya que el riesgo es tan bello" (114d).

No sé como explicarme, pero yo veo en esta observación una muestra de la actitud comedida - por no abusar de la palabra humilde - que debe tener un creyente que se lance a intentar explicarse por su cuenta el conjunto de la realidad y sus últimos secretos, a filosofar, a autoschediazein peri ton theiôn, o, por lo menos, una demostración de que la postura de Sócrates ante la capacidad y el poder de su razón natural y personal no era tan racionalista, tan "liberal", como a menudo se piensa. De esta actitud a la del patriarca de los averroístas latinos, Sigerio de Brabante, cuando sostenía, en varias de sus trece tesis condenadas por el Obispo Tempier, que la teología y los dogmas eran fábulas y que lo único cierto era lo alcanzado por el uso sistemático de la razón, va un abismo en favor de la primera (Mandonnet I, 193: "Siger de Brabant et l'Averroisme latin au XIII siècle" Louvain 1911, T.I., págs 73, ss, 150, 163, etc). La postura de Sócrates no es la del que pretende con su sola razón decir la última palabra sobre lo último. Su actividad filosófica parece más bien como un tantear en busca de una verdad que, por ser más noble que el que la persigue, no siempre y en todas las circunstancias podrá ser captada de hecho de tal modo por éste que pueda estar seguro de haber coincidido con ella...; parece como un riesgo: el de equivocarse. Esta actitud se plasma de una manera perfectamente adecuada en el mito platónico. Al utilizarlo, Platón deja bien sentado que con él no pretende agotar la verdad, que todo lo que en él dice no ha de ser tomado al pie de la letra o completamente en 
serio. No por casualidad deja caer Sócrates, en relación con lo dicho anteriormente, la palabra "mito" al final de su observación.

Pero, ¿por qué razón ha de ser precisamente esta reserva de Sócrates ante la verdad sobre la vida de ultratumba lo que de más valor hay en todo este conjunto? ¿No hace que se pierda con ella gran parte del mérito que representa el anterior hallazgo?

La contestación nos va a dirigir de nuevo al núcleo de la cuestión que queremos tratar: el de las relaciones del intelecto racionalizante e incluso racionalista con la verdad o con las enseñanzas contenidas en una religión positiva - en este caso la griega-. Porque, ¿no ocurre que con esta actitud lo que se consigue es dejar un margen o, mejor dicho, un campo libre para la verdad a secas, escueta, sin mitos, que al hombre le puede llegar desde afuera por obra de una revelación? Sócrates dice en el pasaje a que me he referido últimamente que el afirmar categóricamente la verdad del mito que acaba de contar ou prépei noûn éxonti andri (Fedro 114e). Permítaseme una traducción literal y, sin embargo, no cien por cien exacta de estas cinco palabras: Eso... "no es propio del hombre dotado de razón". Forzando un poco el sentido, se podría leer: "No es propio de la razón humana o del hombre ayudado solamente de su razón”. Pero, ¡éstos no son métodos!, estará alguien a punto de decir. Por suerte tengo preparado para quitar este reproche de la boca, otro texto que dice, esta vez bien a las claras, lo que, no sin violencia, acabo de sacar del anterior. He de confesar que siento una especial predilección por él, con lo cual no extrañará si pido que se ponga al leerlo una atención especial. Su telón de fondo o, mejor, su contexto es la conversación filológica y, más concretamente, semántica que sostienen Sócrates, Crátilo y Hermógenes. Ya 
han descifrado el significado de las palabras más importantes referentes a las cosas humanas, cuando a Hermógenes se le ocurre preguntar si no habría manera de llevar a cabo algo semejante con los nombres atribuidos a las cosas divinas. La respuesta de Sócrates es la siguiente:

Sí, querido Hermógenes, y una muy bella, si procediéramos razonablemente (eíper ge noûn échoimen dice otra vez Sócrates): a saber, decir que sobre los dioses nada sabemos; ni sobre ellos, ni sobre los nombres con que ellos se pueden llamar. Porque está claro que por lo menos ellos dicen la verdad. Pero una segunda manera no es menos apropiada que la anterior: la de llamarles - ya que no sabemos otra cosa - por aquellos hombres con que tenemos por costumbre invocarlos en las oraciones y que son los que a ellos les gusta que utilicemos, pues considero que al hacer esto vamos a llevar a cabo nuestro investigación como si hubiéramos advertido de antemano a los dioses que sobre ellos no investigaremos nada pues no nos consideramos capaces de ello-, sino sobre los hombres, es decir sobre la idea que ellos tenían de los dioses y a partir de la cual les denominaron de una manera u otra" (Crátilo 400d-401a).

El texto entero me parece - sobre todo en boca de un griego- espléndido: Tanto por lo que se refiere a la actitud ante la práctica de la religión positiva, como a la postura que exige del filósofo o simplemente — para decirlo con una palabra en boga- del hombre inquieto por explicarse las cosas. Sócrates cierra su respuesta con la observación de que esto no encierra ningún peligro. Me atrevería a decir que con absoluta razón.

El gran peligro - desde todos los puntos de vista - en que se encuentra nuestro "hombre inquieto" no es el de querer hacerse una idea de todo, el de 
querer hallar explicación —que después puede resultar más o menos verdadera- a todo lo habido y por haber. En esto no veo yo ningún peligro, sino todo lo contrario. El gran peligro, a mi modo de ver, es el de dar demasiada importancia a esta explicación, el de aferrarse a ella, el de considerarla como verdadera pura y simplemente, haciendo girar todo en torno a ella, y, por consiguiente, el de cerrarse a la verdad — “a los nombres con que los dioses pueden llamarse a sí mismos"-, a la verdad que nos es dada sin que tal vez nos la lleguemos a explicar, puesto que no tiene por qué adaptarse a la idea conseguida por nuestro propio esfuerzo. En estas condiciones no cabe duda de que la actitud más sabia es la de no considerar nuestros "hallazgos" filosóficos sino como mitos que no pueden aspirar más que a una mayor o menor aproximación a la verdad... con la ventaja, por otra parte, de que a lo mejor el mito es en el terreno puramente humano o natural el mejor medio de adaptación intelectual adecuada a una realidad — finita - que no sea del todo verdadera. Pero el perseguir el alcance de esta última conjetura me conduciría a un campo netamente platónico, que es mejor dejar para el final.

Sobre el texto últimamente citado no querría añadir más sino que no se trata de un texto accidental. Prueba de ello es el hecho de que Sócrates vuelve sobre él, bastantes páginas más adelante del mismo diálogo, a propósito de una cuestión estrictamente filosófica. Dice Sócrates dirigiéndose de nuevo a Hermógenes:

¿Dejamos de lado esta cuestión o, por si fuéramos capaces de llegar a algún resultado por pequeño que sea, te parece que intentemos examinarla, advirtiendo de antemano lo que poco antes advertimos a los dioses, al observar que, por no co- 
nocer su verdad, no haríamos sino rastrear lo contenido en las opiniones de los hombres sobre ellos? (425b-c).

En otra ocasión, Sócrates y Fedro se encuentran de camino hacia el árbolplátano que va a escuchar el maravilloso diálogo que ambos entretejerán sobre el amor. El lugar que atraviesan está cargado de leyendas mitológicas que Sócrates va recordando a su acompañante. A pocos pasos ya del lugar a donde se dirigen, Fedro pregunta a su amigo y maestro (130e) si él cree en todas esas leyendas. En su respuesta Sócrates se refiere a la inscripción de Delfos. Si él todavía no ha conseguido conocerse del todo a sí mismo, ¿cómo va a intentar determinar lo que en esas leyendas hay de verosímil? Por eso, a él le parece más conveniente renunciar a tal investigación y dedicarse a seguir el consejo de Delfos aceptando, bien entendido, todo lo que corrientemente se cree de esas leyendas. Al leer este texto no cabe duda de que no se puede dejar de percibir un ligero tono irónico en las palabras de Sócrates: risible sería investigar todas esas cosas extrañas a mí (allótria) no conociéndome a mí mismo. Un tono que, sin embargo, no impide que el contenido sea muy de tener en cuenta. El incrédulo que quisiera investigar con su razón todas esas leyendas, no conseguiría más que eso: reducir todo a lo verosímil (katà to eikós), dice Sócrates, y en esta expresión se encierra la idea de una imagen como sustitución de la verdadera realidad y a la vez de la mera posibilidad. De reducir, efectivamente, todo a lo verosímil a alcanzar la verdad dista todavía, por tanto, un buen trecho, por lo cual no sería mucho lo que se hubiera conseguido. En el fondo de esta consideración late la convicción de que no merece la pena substituir lo que tal vez de hecho no pueda aspirar 
más que a ser una copia probable de la realidad por aquello que, por poco verosímil que parezca a nuestra razón, consiste precisamente en esa aspiración a la verdad.

Esta convicción puede proporcionar indudablemente un buen punto de partida para determinar satisfactoriamente las relaciones entre la actividad autónoma de nuestra inteligencia en su deseo de "explicarse" las cosas —una "explicación" que quizás no pasa de dar con lo "verosímil", con una aproximación probable de la realidad - y nuestra buena disposición para recibir lo heteronómicamente dado, lo estrictamente verdadero.

Pero tal vez me haya excedido en la interpretación del último texto, ya que en él no se dice en principio nada en contra de la posibilidad de una ciencia puramente humana, de la que pudiéramos pensar que estuviera en disposición de llegar a resultados absolutos, sino que se habla simplemente en relación con leyendas mitológicas. Y esa otra ciencia bien pudiera ser precisamente la que encamina sus esfuerzos hacia el conocimiento del alma humana, o sea la filosofía. Pero también esta vez estoy bien protegido contra este reproche, ya que le puedo hacer frente incluso sin necesidad de salirme del mismo diálogo para irme a buscar textos más apartados —en todos los sentidos- como aquellos del Banquete en que Sócrates establece la diferencia entre el verdadero sabio y el filósofo. Este otro, a que ahora me refiero, no sólo se encuentra igualmente en el Fedro, sino que además muestra un paralelismo tan claro con el anterior que no puede por menos de ser considerado como una declaración de éste. Y, porque es más corto, lo voy a copiar entero. De lo que va tratando Sócrates es, precisamente, del alma; de su inmortali- 
dad, un poco antes, y de su esencia, ahora. En este momento aparece el pensamiento que nos interesa:

Para saber qué sea el alma (oion men estin) se requiere una disquisición totalmente divina y grandiosa; para saber, en cambio, a qué se parece (ho de eoiken) basta una humana y más reducida" (Fedro 246a).

También en este terreno se ha de contar, pues, con otro saber superior al que el hombre pueda alcanzar de hecho por sí mismo, puesto que este último no pasa de ser un andar a tiendas en buscar de la verdad, sin que pueda llegar a ella sin mezcla de error.

Una vez determinadas así las regiones que corresponden a cada uno de estos dos modos de saber sería cosa de preguntarse por el papel que juega cada uno de ellos en la opinión de Sócrates y de Platón: qué importancia cobra la primera en orden a la formación humana y qué cometido cabe entonces atribuir al otro saber dado que se da por descontado que tal vez no nos va a proporcionar la verdad pura y simplemente (nullo admixto errore). Si se nos da, efectivamente, la verdad ¿por qué andarse con tantos rodeos? ¿Qué justificación puede tener todavía el ejercicio autónomo de la razón? Con esto tendríamos que plantearnos de nuevo la cuestión referente a la razón de ser de una postura humanística o estrictamente filosófica ante los últimos problemas que al hombre se le plantean. 
Colocados frente a esta segunda cuestión, no caben sino dos posibilidades: o rechazar toda justificación de una filosofía "pura" - que no quiere decir, como es lógico, sin presupuestos ${ }^{1}-$ o, si nos empeñamos en seguir admitiendo el derecho a la existencia de la filosofía como quehacer puramente racional, no hay más remedio que buscar las bases para que el creyente pueda hacer auténtica filosofía y no una mezcla de cosas, con un valor en algunos casos superior, por supuesto a la filosofía, pero que de todo tienen menos de aquello que pretenden ser: filosofía.

Por muchas razones, que ahora no quiero enumerar, me inclino resueltamente - por lo menos por ahora - a esta segunda posibilidad. En estas condiciones, ¿no parece una buena solución, apetecible y ventajosa, la fórmula de Sócrates respecto a la actitud que ha de tomar un creyente interesado por llegar a la mayor claridad posible — de acuerdo, nada más que intelectual, es decir, puramente intelectual一, ante los más profundos problemas filosóficos? De otro modo, se cae en el peligro de que la filosofía, por el hecho de tener el filósofo una fe, la verdad pura y simplemente, no llegue a ser nunca filosofía o se pase siempre de la raya sin haberlo sido nunca y, en consecuencia, no sirva más que para edificación de los que por descontado están dispuestos a aceptar sus conclusiones - lo cual no estaría del todo mal- o para regocijo de los que no lo están tanto - lo cual ya no está tan bien-. Aquí sería ya ahora de aplicar a este terreno la solución que san Agustín dio a

${ }^{1}$ La autonomía de la filosofía no consiste en que esta no presuponga nada, sino que no se proponga demostrar cuestiones ajenas a su "nómos" propio. De ahí la importancia del "juego libre y desinteresado de la imaginación trascendental". 
la vertiente metafísica de esta cuestión: la infinitud de Dios es tal —es decir, es de tal manera realmente infinitud- que Dios se puede constreñir libremente a no ocupar - por así decirlo- un lugar, del que, por derecho, hubiera podido posesionarse: por ejemplo, la libertad del hombre. Esta autolimitación no va en menoscabo de su infinitud. Al contrario, es una consecuencia de ella. Los vericuetos metafísicos que conducen a esta solución no nos interesan aquí, pero sí su aplicación rápida al tema de esta introducción. El problema es el de potenciar al máximo todo lo que de divino hay en el hombre y a la vez lo que de noble y específicamente humano se encuentre en él: su heteronomía y su autonomía.

Precisamente porque el cristiano está en posesión de la verdad, habría de tener - tiene - la oportunidad de abandonarse libremente a su pensamiento para ver hasta donde llega con él —una oportunidad que a lo mejor, en el fondo, no la tienen en igual medida los demás-. ¿Un juego? Probablemente; más aún: sin duda alguna. Pero ¿quién ha dicho que en el juego - ien el mito!- en lo ficticio, en lo verosímil, no está encerrada la clave de lo real, pero no estrictamente (schlechthin) verdadero, de lo aparencial y ficticio, pero no por ellos menos vital, de lo no-verdadero, pero no por ello falso en el hombre, en el universo, la clave de eso tan difícil de aprehender como es la "mundicidad del mundo", la "Weltlichkeit der Welt”? ¡Cuánto podemos aprender también de Schiller en este terreno (el "freies Spiel der Einbildungskraft" como lo específicamente humano) y cuánto también de Platón y sobre todo del principio de la parte estrictamente filosófica de su Timeo (29a y ss), como al final veremos! 
Una cosa está clara y es que el cristiano puede también prescindir de todo esto, puesto que está en posesión de la verdad pura y absoluta, que, por lo tanto, la posición bastante desairada de la filosofía de los cristianos hoy día no le tiene que perturbar en la entraña más íntima de su ser. Afirmar otra cosa sería olvidar que aquél ha de considerar su triunfo definitivo desde una perspectiva escatológica. Pero que esta renuncia, que esta huida del mundo - y la filosofía es una de las expresiones más altas del mundo "como mundo" - haya de constituir la regla, es lo que, por lo menos, no es tan evidente. Y si esto último es así - a mí me parece no sólo probable, sino casi completamente seguro- ¿por qué tanto cortarse las alas? ¿A santo de qué quedarse siempre en actitud defensiva o - a lo más- de expectativa ante lo que los demás piensen?

"Sub specie aeternitatis" no hay progreso alguno. Esto es evidente. Pero, ¿es connatural al hombre, responde a su naturaleza, el considerar "todo" —es decir "todo" - nada más que "sub specie aeternitatis"? No pertenece a la esencia del hombre otra estructura que, tal vez no del todo verdadera, no por ello deja de serle consubstancial: la de la temporalidad y la de la historicidad? "Sub specie temporis" existe un progreso, y dejar que éste sea realizado en éste o en aquél solo por los del siglo o los siglos de las luces pudiera ser - por lo menos - una falta de responsabilidad. ¿Qué más da —al contrario- si después resulta que ese progreso no es más que un acercarse al principio, a las fuentes?

El instalarse en este punto de vista de afirmación rotunda de todo lo positivo requiere tensiones para las que tal vez los nervios o la cabeza o el corazón 
—o las tres cosas- no están del todo preparados. En España nos hemos pasado por lo menos medio siglo afirmando que "urge" emprender esto o aquello, que "urge" revalorizar aquello y lo de más allá. Basta repasar la literatura ensayística, sobre todo durante su época de esplendor -época ya, por fortuna, algo lejana-. Y probablemente en estos gritos de urgencia se nos ha ido toda la fuerza. Permítaseme que caiga ahora en el mismo defecto y que haga aumentar en una el número de las urgencias que en todas las revistas culturales españolas habrán aparecido en lo que va de año. Después de todo, en mi caso tengo la excusa de que aquí no se trata ni tan siquiera de un ensayo, sino de una mera introducción. Pues bien, creo que urge ejercitarse, adiestrar - casi diría ascéticamente- la cabeza y el corazón y los nervios para poder exponerse a esas tensiones. Las referentes a la cabeza se llaman contradicciones. $Y$ creo que es en este punto donde se pueden abrir las mayores perspectivas a la filosofía que haya que crear en España. Nada de esto tiene lo más mínimo de revolucionario. Algo de corazón se requiere - es cierto- para atreverse a tomar posesión de una estructura mental en la que la contradicción se encuentre plenamente a sus anchas. Tanto es así que ni Platón se atrevió a seguir este camino a pesar de haberlo vislumbrado como ningún otro (Sofista 239c4; 258e8). Pero ¿̇no es la contradicción el nervio de la dialéctica hegeliana? Y ¿no continúa viviendo de ella la mayor parte de la filosofía actual? $Y$ ¿no nos ha dicho un pensador, para el gusto de algunos tan pacato, como Menéndez y Pelayo que la filosofía cristiana no volverá a tomar la dirección del pensamiento humano mientras no sea capaz de hacer con Hegel lo que Santo Tomás - contra viento y marea- hizo con Aristóteles? Yo también soy de aquellos a quienes Menéndez y Pelayo — sobre todo por 
prejuicios y tal vez en parte también por oír hablar tanto de él como de Don Marcelino - resulta algo pacato; pero si esto dijo alguna vez, le considero mucho más valiente que aquél otro que para renovar el pensamiento español acudió a un tal Krause.

Hegel sí, Hegel es algo muy serio y lo positivo es que él supo encontrar en la contradicción algo que todavía sigue dando qué hacer por el mundo. Hace poco se me escapó una frase bastante exacta, aunque desgraciadamente, no muy bien-sonante: la de potenciar al máximo todo lo divino y lo humano. Con ello quería decir que, si el hombre tiene una capacidad equivalente a 100, debe llenar esas 100 unidades de lo divino - lo divino ha de ser para él el 100\%- y a la vez debe llenar un tanto por ciento muy elevado de esas mismas 100 unidades con lo humano. Algo contradictorio. Imposible, se dice. En cambio, hay quien dice que lo ha experimentado, y Lope de Vega, que el que lo probó lo supo. A mí me parece que no estaría de más buscar un esquema racional donde cupiera esa contradicción: dos veces cien por cien por el mismo cien - que no den doscientos por cien sino ... otra vez cien por cien.

Pero se podría presentar una duda: ¿Y si la mente en ese quehacer autónomo — uno de los cien por cien - llegara a la conclusión de que no se debe parar donde hemos dicho, que debe considerar sus hallazgos no sólo como verosímiles, sino incluso como verdaderos? La objeción no es, desde luego, ligera. Toca la pulpa misma de la filosofía. Lo que con ella queda puesto sobre el tapete es nada menos que la existencia misma de ésta; pero no es insuperable. Irrebatible es, por el contrario, según me parece, la respuesta: admitido que la razón autónoma llegase a aclararse todo sin dejar ningún 
resquicio por iluminar —es lo que creyó, por cierto, Hegel poco menos que haber conseguido con su dialéctica- siempre quedaría un respeto inexplicable: ¿quién, sino la misma explicación, nos podría convencer de que la realidad explicada requiere una explicación? El presupuesto de que la realidad es explicable no puede ser reducido jamás a explicación. Y es precisamente la misma irreductibilidad de este presupuesto lo que nos da la garantía de que nuestra explicación no puede aspirar nunca a proporcionarnos la verdad absoluta y, por tanto, de que la actitud de Sócrates ante ella es la única posible para uno que persiga la problemática hasta el final. Supongamos que la realidad fuera absolutamente inexplicable. Si así fuera, no habría nada que nos la pudiera explicar ni tan siquiera que nos pudiera mostrar que es inexplicable, ya que esto último significaría ya una explicación, desde el momento en que para llegar a semejante afirmación habría que explicarla antes. En este supuesto — de una realidad absolutamente inexplicable - está implicado el presupuesto de que a la realidad se le pueden arrancar en mayor o menor medida sus secretos, de que la realidad es explicable. Esta consideración que constituye el núcleo más hondo del pensamiento de Nietzsche, aunque en él conduce a otras consecuencias - es precisamente lo que quita el veneno a la filosofía sin arrancarle el aguijón, puesto que ésta, la filosofía, será siendo una necesidad primordial del hombre consustancial a su esencia y afilándole, por el contrario, el mordiente... aunque no sea más que para llegar a conclusiones “aparienciales". Porque, a propósito de esto último, ¿no es el hombre, como dijo una vez Ortega y Gasset - con motivo de la muerte de Schelerun extraño pájaro que se alimenta con sus propios errores? ¿Y no hay algo de verdad en una frase escrita por Heidegger en el prólogo a la segunda edición 
no corregida de su libro sobre Kant a la vista de las críticas que se habían hecho a la primera, a las cuales él daba toda la razón... con la reserva de que los auténticos "pensadores piensan con más intensidad a partir de lo imperfecto"?

Pero volvamos a nuestro Sócrates.

Considera Platón en un diálogo, que, por describir detalladamente el método mayéutico, es probable que refleje bastantes ideas socráticas, la diferencia entre el modo de proceder de los que tienen que hablar, como los abogados, para defender una causa o escribir, o como los poetas, para ganar un premio, y el de los filósofos, que no se ven sujetos por ningún objetivo previo que alcanzar, que no tienen por qué temer el fallo de ningún jurado y que, por lo tanto, pueden ser considerados, al revés que aquellos, como luchadores - "agonistas" - libres de todo compromiso y de todo prejuicio. No son ellos los que se tienen que someter al discurso, sino éste el que se tiene que someter a ellos, de modo que en sus manos está emprenderlo cuando quieran, interrumpirlo cuando les parezca bien, cambiar de tema cuando lo crean oportuno y detenerse en el nuevo todo el tiempo que juzguen conveniente. Los demás, los siervos del discurso, saben de antemano qué es lo que tienen que considerar como verdadero, lo sea o no. Esta es la diferencia entre abogados, poetas y los servidores de la ciencia más alta. Aquéllos que no se pueden permitir el lujo de cambiar de opinión, aunque lo consideren más razonable, ya que por medio está la "causa" (así traduce, creo que acertadamente, Schleiermacher: die Sache 172e7) y, a menudo, nada menos que la vida. Los alemanes tienen dos palabras que nos dan de un solo brochazo estas dos posturas y que ahora voy a utilizar —abandonando de nuevo el 
contenido directo del texto platónico- para referirme más bien a la fe religiosa y a la filosofía: bekennen y erkennen. Bekennen es confesar algo en el sentido de pronunciarse por ello; erkennen es penetrar racionalmente en el sentido de algo, comprenderlo. La primera vez que he visto enfrentadas estas dos palabras ha sido en una de las introducciones a la Ciencia de la Lógica de Hegel. Y, naturalmente, el racionalismo absoluto de Hegel arremete con la primera, lo cual a nosotros aquí nos tiene muy sin cuidado. Entre otras cosas, porque ya he apuntado el motivo fundamental para rechazar un racionalismo absoluto. Pero volvamos a nuestras dos palabras.

Se confiesa — se profesa - una religión, aunque no se penetre racionalmente en todos sus misterios. En cambio, se comprende o hay que esforzarse por comprender todo aquello de que no nos podemos servir antes de haberlo comprendido. Las dos actitudes pueden ir, por tanto, paralelas, sin llegar a colisiones, lo cual no significa, naturalmente, que no puedan ir juntas por muchas otras ocasiones. Pero qué consecuencias tan fatales no trae el mezclarlas o el usar la una por la otra y viceversa en cuestiones que de suyo requieren la separación antes dicha. Entonces se llega, por un lado, a la actitud antes apuntada de Sigerio de Brabante y, por otro, a consecuencias tal vez no tan fatales, pero no por ello menos equivocadas, por ejemplo, cuando se intenta pontificar donde no hay por qué o cuando se pretende investigar dónde está una solución determinada y se pone uno en camino con la solución, entera y absolutamente segura, en el bolsillo.

¿Qué quiere decir enfrentarse desde el punto de vista cristiano con el problema de si el sol da vueltas alrededor de la tierra o al revés? ¿No consiste aquí el punto de vista cristiano más bien en tratar la cuestión utilizando todos 
los medios técnicos y científicos a nuestro alcance y ofrecer esa actividad a Dios? (Recomiendo, por la fina ironía que encierra, la lectura del siguiente pasaje platónico: Político 298c,d). Porque a lo mejor resulta que la utilización de todos estos medios científicos y técnicos no nos van a impedir caer en el error respecto de este problema concreto.

No tiene demasiada importancia caer en el error, con tal de no confundirlo con la verdad. Después de todo, salvo buena parte de la filosofía tomista, todas las filosofías en su esencia no constituyen más que una colección de "ficciones" ${ }^{2} \mathrm{Y}$, en cuanto a la única filosofía verdadera en su esencia, sobre este tema no sabría ahora decir nada más que no siempre el intelecto humano resiste la verdad, como tampoco el ojo humano resiste siempre la luz del día y, por eso, prefiere en algunos momentos la tiniebla de la noche. Pero, porque me estoy metiendo en el terreno político que, en este caso, para mí es como la noche, prefiero dejar hablar por mí a unos versos maravillosos que sobre ella escribió Hölderin en su elegía Bröt und Wein.

Wunderbar ist die Gunst der Hocherhabnen und niemand

Weiß, von wannen und was einem geschiehet von ibr.

So bewegt sie die Welt und die hoffende Seele der Menschen,

Selbst kein Weiser versteht, was sie bereitet, denn so

Will es der oberste Gott, der sehr dich liebet, und darum

Ist noch lieber, wie sie, dir der besonnene Tag.

Aber zuweilen liebt auch klares Auge den Schatten

${ }^{2}$ Lo trágico aquí no es que esos autores cayeran en ellas, sino que las confundieran con la verdad. 
Und versuchet zu Lust, eh es die Not ist, den Schlaf,

Oder es blickt auch gern ein treuer Mann in die Nacht bin,

$J a$, es ziemet sich, ibr Kränze zu weibn und Gesang,

Weil den Irrenden sie geheiliget ist und den Toten,

Selber aber besteht, ewig, in freiestem Geist.

Aconsejo también la lectura de toda la séptima estrofa ${ }^{3}$ :

Tarde, muy tarde llegamos, que ya los dioses se fueron.

Cierto es que siguen viviendo, pero de los humanos muy lejos, todos en otra región. Siempre obran ellos allí.

\footnotetext{
${ }^{3}$ Aber Freund! wir kommen zu spät. Zwar leben die Götter,

Aber über dem Haupt droben in anderer Welt.

Endlos wirken sie da und scheinen's wenig zu achten,

Ob wir leben, so sehr schonen die Himmlischen uns.

Denn nicht immer vermag ein schwaches Gefäß sie zu fassen,

Nur zuzeiten erträgt die göttliche Fülle der Mensch.

Traum von ihnen ist drauf das Leben. Aber das Irrsal

Hilft, wie Schlummer, und stark machet die Not und die Nacht,

Bis daß Helden genug in der ehernen Wiege gewachsen,

Herzen an Kraft, wie sonst, ähnlich den Himmlischen sind.

Donnernd kommen sie drauf. Indessen dünket mir öfters

Besser zu schlafen, wie so obne Genossen zu sein,

So zu harren, und was zu tun indes und zu sagen,

Weiß ich nicht, und wozu Dichter in dürtiger Zeit.

Aber sie sind, sagst du, wie des Weingotts heilige Priester,

Welche von Lande zu Land zogen in heiliger Nacht.
} 
Y no parece que atiendan siquiera si es que nosotros vivimos.

¡Tanto preservan al hombre!, pues que no siempre resiste débil vasija acogerlos. Sólo en algunos momentos, sólo en muy pocos momentos, resiste el hombre sus rayos. Sueño de ellos es luego toda la vida en la tierra.

Pero el error ayuda, cual sueño, y la noche y penuria confortan al hombre, hasta que un día los héroes crecidos en cuna de hierro surjan de nuevo igual que los dioses.

... En tanto parece mejor...

dormir y soñar...

En otro orden de cosas, también me parecen acertadas a este respecto unas palabras de Menéndez y Pelayo. Se refieren al platonismo español y se encuentran en la página 62 del Tomo II de las Ideas estéticas en España (ed. del CSIC):

Por otra parte, no hay escuela, por alta, por noble que sea, cuya vitalidad no se agote, cuando sus secretarios ruedan eternamente en el mismo círculo durante dos siglos. Entonces se cae en el amaneramiento científico, hermano gemelo del amaneramiento literario. Es señal cierta que aquel modo de pensar ha dado de sî cuanto podía dar, y es necesario cambiar de rumbo... Tal aconteció a la estética idealista y platónica, cuya juventud tan vigorosa y tan audaz hemos admirado en León Hebreo. Sucumbió, pues, por el agotamiento de fuerzas, y luego por el silencio, no interrumpido en todo el s. XVIII por la voz extranjera de Hengs, a quien refutaron sus amigos españoles. $Y$ cuando el idealismo volvió a imperar, no fue ya bajo su forma antigua, sino transformado enteramente por Hegel. 
Creo que Menéndez y Pelayo tiene razón, que se necesita juventud, vigor y audacia para dar vida a muchas cosas, por ejemplo, a la filosofía, y que esa juventud, ese vigor y esa audacia han de empezar o se han de probar aprendiendo a mirar de cara al error, a la falsedad, a lo que no es verdad - a la Unwahrheit-y sin embargo sí es muy real, demasiado real, muy humano, demasiado humano (lo cual no quiere decir que la filosofía tomista no haya de ser estudiada constantemente como depositaria de la verdad — de la revelación - en vasijas filosóficas); aprendiendo a tomar en serio eso de echarse a soñar, la noche, lo ficticio, el mito. $Y$ es otra vez a Hölderlin, a la misma elegía, en su octava estrofa, a quien voy a dejar la palabra final de este intermedio, como resumen del mismo:

Darum singen sie auch mit Ernst, die Sänger, den Weingott

Und nicht eitel erdacht tönet dem Alten das Lob.

"Placet experiri": es la consigna que da el pobre Settembrini al bisoño Hans Castorp. Y es así. Al hombre le gusta experimentar, probar sus fuerzas, jugar con el error; "elementa speculare" — como al padre de Adrian Leverkünhn—, pero no tanto por amor a la verdad — de la verdad se acuerda en general poco- como por una extraña proclividad hacia el error. Pero después resulta que es así como progresa. El "experiri” — sin dar lo experimentado como la verdad, que es aquí el único peligro, lo que hace del jugar con el error un jugar con fuego: sobre todo esto quiero hablar ahora a propósito de Platón, que ya va siendo hora de que volvamos a él一, el "expe- 
riri" tiene indudablemente un gran valor. No se cansó de gritarlo el padre de la ciencia experimental moderna, el franciscano Roger Bacon, de advertir que si no nos dábamos cuenta de ello, la ciencia cristiana nunca se pondría a la altura de la árabe y de la judía (Friedrich Herr. Europäische Geistesgeschichte, Stuttgart, 1953: 149). Y, salvo el Papa Clemente IV, ¡quién en su época le hizo caso! Es, en otro terreno, la misma urgencia de la que hablaba antes.

Pero, a todo esto, ¿qué hemos hecho de Platón? ¿Nos ha dicho ya todo lo que nos tenía que decir? ¿No nos podrá seguir ayudando a ver en estas cuestiones con más claridad... y con más serenidad de la que, según ya frase hecha, sólo él poseía el secreto? Yo creo que sí. Sólo que para comprobarlo hemos de adentrarnos en un terreno algo más difícil y distinta: el del Sofista, primero, y el de Timeo, después. Más difícil el del Sofista, porque se trata del diálogo central para la ontología platónica; más distante de las orillas de donde zarpamos, porque en él no lleva ya la voz cantante Sócrates, sino el extranjero de Elea. De todos modos, las ideas contenidas en él, a las cuales me voy a referir, concuerdan perfectamente con las ya comentadas y que Platón expresa por boca de Sócrates en otros diálogos.

Ya bastante avanzada la caracterización del Sofista (240), Teeteto se ve obligado por el extranjero de Elea a determinar con más precisión lo que él entiende por eidōlon. En la respuesta, la "imagen" queda caracterizada como lo que se parece a lo verdadero sin serlo, o sea, como lo verosímil (eoikòs 240b2). La idea que nos formamos de la realidad, aquello que construimos con nuestro propio esfuerzo mental es por lo tanto, un eikōn (240b13), una imagen más o menos aproximada de la realidad, pero no la misma realidad. Es verdad que Platón hace esta observación al intentar definir al sofista. Pero 
aquí está precisamente lo más interesante. Porque no es simplemente el hecho de que el sofista no dé con la verdad lo que hace de él un sofista. Por el mero hecho de decir algo que se parezca a la verdad no se es ya sofista. Lo que hace del sofista un sofista es que se conforma con eso, más exactamente, que lo toma por verdadero o, todavía mejor, que, aun a sabiendas de que no es así, hace pasar la imagen verosímil por la realidad verdadera, lo que no es por lo que es (240d-241). Por eso, hay que distinguir entre la falsedad (pensar que lo verosímil es lo verdadero) y la no-verdad (no pensar tal, sino quedarse en la aproximación como aproximación). Quien, por tanto, se conforma con la imagen como imagen, sin pretender tomarla por la verdad, no cae en la falsedad, aunque tampoco llegue a la verdad. Y este sería el papel de la filosofía. Que esta última afirmación no aparece expresamente en el Sofista es completamente exacto. Pero ¿̇no está en perfecta armonía con la idea que de la filosofía tenía Platón y que éste, por ejemplo, pone en boca de Sócrates, en la alabanza que del amor pronuncia en el Banquete? El amor, es decir, el amor de las ideas (Fedro 278d) propio del filósofo, es el hijo de Poros y de Penía, concebido durante los festejos con los que se celebró el festejo de Afrodita. Y es su madre Penuria la causa de que nunca pueda ver colmado sus deseos de conocimiento, sino que se tenga que conformar con un estado medio entre la sabiduría y la ignorancia. "Ninguno de los dioses, en cambio, desea ser sabio, porque ya lo son y si algún otro ser, aparte de ellos, fuera también sabio, ese tampoco filosofaría" (240a1-4).

La filosofía es para Sócrates una sabiduría para andar por casa, algo así como el arte divinatoria de que éste decía estar en posesión y que, como la escritura de aquellos que no la dominan bien, sólo sirve para uno mismo, 
pero no para enseñarla como una obra acabada, según confiesa el mismo Sócrates a Fedro (Fedro 242c5). En estas condiciones, es imposible seguir llevando demasiado lejos la ironía socrática o, mejor dicho, interpretarla mal y considerar, de esta manera, algo así como un mero recurso retórico o, a lo más dialéctico en el sentido aristotélico ${ }^{4}$, lo que dice en el Teeteto sobre la mayéutica: que con ella no pretendía inculcar a los demás su filosofía, los resultados, siempre relativos, a que por medio de ella llegaba, sino sencillamente ayudar a los demás a crearse su propia filosofía. Este aspecto personal de la filosofía, debido entre otras cosas sobre todo al origen de la misma a partir de Poros y Penía, no desapareció nunca de su horizonte mental y así se explica que la filosofía no fuera considerada por él nunca como un sustitutivo del saber más alto $-\mathrm{o}$ de la piedad-, sobre los nombres con los que los dioses quieren ser invocados en las oraciones por los hombres.

¿Queda todo ahí?

Yo creo que no, y confío en poder decir todavía lo más importante a este respecto en relación con la filosofía. Si aquí pretendiera poner el punto final, no cabe duda de que, después de tanto prometer llevar a cabo una defensa de su autonomía a pesar de reconocer su papel secundario, la habríamos dejado en una situación bastante desairada. Porque aquello de la proclividad natural del hombre al error o hacia la no verdad, según los casos, (¡qué lástima que no exista en castellano la palabra correspondiente a la alemana Unwahrheit) es un intento bastante flaco de justificar la filosofía como quehacer humano.

${ }^{4}$ De todos modos, parece que la opinión aristotélica sobre la dialéctica no era tan peyorativa como se ha venido creyendo. 
Hasta ahora los filósofos no se nos han aparecido sino como una especie de teólogos inexactos, empleados en conjurar fantasmas - no de exorcizarlosy quimeras y, lo que es aún peor, extraordinariamente tercos.

¿No nos podrá sacar Platón, ese maestro en sacar de apuros, de éste en el que al final nos hemos visto envueltos? Platón da en ciertos casos una extraordinaria importancia a la idea de Pistis entendida como confianza. Vamos a abandonarnos confiadamente a él en la esperanza de que también nos sacará de esta dificultad.

Que se trata en nuestro caso de una inmensa dificultad ya lo experimentó él mismo antes que nosotros. Hasta el punto de que una vez dijo que del encuentro con lo quimérico, con lo fantasmagórico, con lo ficticio, surgía ineludiblemente la megista aporía (Sofista 238a), la dificultad más grande de todas y, si tomamos la palabra megistón en el sentido en el que se le da en las tragedias griegas, la dificultad más que grande, enorme, desmesurada. Pero si, como decía Hölderlin: "Wo aber Gefabr ist, wächst der Rettende auch", en este caso podemos poner nuestra confianza en que de este enorme peligro lograrán sacarnos las no menores espaldas de Platón. Porque, en efecto, de sus palabras se deduce claramente que tiene cierta familiaridad con él y, lo que no es menos importante, que está dispuesto a abordarlo de frente.

"Sí, querido Teeteto" — dice el extranjero de Elea-. "El aparecer y el pensar lo que no es, así como el hablar de lo que no es verdad, todo esto ha estado siempre lleno de dificultades y sigue estándolo ahora" (Sofista 236d,e). Por un momento, sin embargo, cree Teeteto que el asunto queda zanjado diciendo que los que tal hacen no solo dicen lo que no es, sino que incluso no dicen nada (télos goûn an aporías ho lógos échoi, 237e). Pero el eleata lo ataja 
para desengañarle: le dice "al contrario, la cuestión sigue en pie y es incluso la mayor y la primera de todas las dificultades" (peri gar autén auto (tou lógou) tèn archèn ousa tugchánei, 238a). A continuación intentan los dos ver si el hablar de la verdad, de lo que es, resulta más fácil que el hablar de la falsedad, de lo que no es. La esperanza resulta vana, pero de ahí, dice el extranjeextranjero, se desprende una nueva: la de que, puesto que el ser y el no ser, lo verdadero y lo verosímil están envueltos en las mismas dificultades - lo uno por la luz excesiva que acompaña al ser y lo otro por la oscuridad en la que se oculta el no-ser- habrá que pensar que al conquistar uno de los dos se nos rendirá también el otro. (250e). Y es aquí donde hemos de recurrir al Timeo para ver el sentido más profundo de esta última esperanza. En el principio de la parte propiamente filosófica de este diálogo reina el mismo clima que en los pasajes citados del Sofista. Allí se nos apareció la dificultad que ofrece el tratar de lo verosímil como lo más importante, y como el principio de la cuestión que el extranjero quiere tratar. Aquí, Timeo insiste en estos dos aspectos diciendo que lo más importante de todo (mégiston dè pantós) es comenzar de una manera adecuada a la naturaleza de lo que se va a tratar (árxasthai katà phúsin arcôn ). Y de lo que se va a tratar es del mundo aunque, conviene no olvidarlo, como preparación para continuar con el tema del Estado de que se habló en La República-. Ahora bien, el mundo se acaba de ofrecer en el párrafo anterior del diálogo como una "imagen" (eikōn) que resulta del hecho de que, al mirar el demiurgo hacia las ideas (paradeígmata), el caos inicial —el no ser del mundo- queda ordenado de tal manera que constituya un fiel reflejo de éstas. Se trataría aquí — según el testimonio de Aristóteles en el De Caelo— de una visión del tipo de la que el matemáti- 
co tiene ante una figura trazada en el papel: la figura en sí tal vez no constituya una entidad matemática - porque los lados dibujados del triángulo, por ejemplo, no son realmente rectos-; pero desde el momento en que un matemático opera con ella, adquiere la figura deforme ser matemático por el hecho de que el matemático proyecta en ella la idea verdadera del triángulo. De la misma manera, el caos, gracias a la ordenación del demiurgo, se convierte en una auténtica imagen del mundo de los paradigmas o de las ideas; pero - $-\mathrm{y}$ esto es lo más importante- aquí el mundo no es más que eso: una imagen $^{5}$. Tal es la naturaleza de lo que se ha de tratar y a la que hay que acomodar el discurso desde el principio ${ }^{6}$. Esta es la tarea más importante y de la que dependen como de su principio todas las demás. Tratándose de los paradigmas, el discurso habrá de ser del mismo género que estos: irrebatible (analenktos), inmóvil (akinetos); en cambio, tratándose de una reproducción verosímil de aquellas, de una imagen, el discurso habrá de ser análogamente (anà lógon) una imagen apropiada de lo verdadero. Será necesario, pues, otorgar nuestra confianza a este discurso, a pesar de no ser completamente seguro, ya que, en cambio, lo verosímil propio del mundo como imagen que

${ }^{5}$ Toúton de hyparchonton au pasa ananké tondé ton kosmos eikóna tinos einai. (Timeo 29b): "Si esto es así, es de toda necesidad que este mundo sea una imagen de algo". (Nota del editor: se incluye aquí, y en las demás citas extensas, la traducción de Gredos, para facilitar al lector el acceso al texto, que Inciarte dejó solo en griego).

${ }^{6}$ Hōde oûn perì te eikònos kaì perì tồ paradeìgmatos aues dioristèon, hōs àra tous lógous, hōnper eisin exēgetai, toutōn autōn kaì sungeneîs óntas. (Timeo 29b): "Entonces, acerca de la imagen y de su modelo hay que hacer la siguiente distinción en la convicción de que los discursos están emparentados con aquellas cosas que explican”. 
es y del mito (como imagen de esa imagen) es al ser (de los paradigmas), “como la confianza a la verdad" (Timeo 29c).

Pero aquí nos asalta una duda. Es verdad que Platón habla del mundo como una imagen y del conocimiento adecuado a ese mundo no completamente verdadero como de otra imagen (el mito), como de algo que es verdadero y a la vez no lo es (República, II, 377a): Solamente lo demónico (en sentido griego) y lo divino es estrictamente verdadero (República, II, 382e), "nullo admixto errore". Pero — y esta es la duda— ¿no se refiere con ello simplemente al conocimiento que del mundo tiene el hombre, dejando intacto - como plenamente verdadero- el conocimiento que el hombre tiene de las ideas y del demiurgo o Dios? Y ¿no es la filosofía el conocimiento de las ideas? La duda no está justificada. En primer lugar, ya sabíamos por el Banquete y por el Fedro que la filosofía no es tanto el conocimiento de las ideas como el amor de las mismas. Pero, por si esto fuera poco, Platón se encarga de apartarnos esta duda en el párrafo siguiente al que hemos comentado. De él se deduce que el fundamento para considerar nuestro conocimiento como una imagen es doble: en primer lugar, viene dado por la realidad imaginaria (pero no por eso menos real) del mundo que nos rodea, pero, en segundo lugar, se debe también a la misma naturaleza del hombre. Por lo tanto, conozca este el mundo (una imagen) o conozca los paradigmas de esa imagen - las ideas, las cosas divinas- el conocimiento que le corresponde y el único que le es adecuado (que es para él verdadero) es el verosímil. "De modo que conviene aceptar sobre todas estas cosas (las divinas y las humanas) el mito vero-simil y no exigir más de nuestro conocimiento". 
Sócrates, que es su interlocutor, no puede por menos de contestarle: "Oh, Timeo, de muy buen grado hay que asentir absolutamente a todo lo que dices" (Timeo 29d).

Pero, como es texto es muy importante, lo voy a copiar entero:

Timeo: Si esto es así, es de toda necesidad que este mundo sea una imagen de algo. Por cierto, lo más importante es comenzar de acuerdo con la naturaleza del tema. Entonces, acerca de la imagen y de su modelo hay que hacer la siguiente distinción en la convicción de que los discursos están emparentados con aquellas cosas que explican: los concernientes al orden estable, firme $v$ evidente con la ayuda de la inteligencia, son estables e infalibles — no deben carecer de nada de cuanto conviene que posean los discursos irrefutables e invulnerables-; los que se refieren a lo que ha sido asemejado a lo inmutable, dado que es una imagen, han de ser verosímiles y proporcionales a los infalibles. Lo que el ser es a la generación, es la verdad a la creencia. Por tanto, Sócrates, si en muchos temas, los dioses y la generación del universo, no llegamos a ser eventualmente capaces de ofrecer un discurso que sea totalmente coherente en todos sus aspectos y exacto, no te admires. Pero si lo hacemos tan verosímil como cualquier otro, será necesario alegrarse, ya que hemos de tener presente que yo, el que habla, y vosotros, los jueces, tenemos una naturaleza humana, de modo que acerca de esto conviene que aceptemos el relato probable y no busquemos más allá.

Sócrates: Absolutamente bien, Timeo, y hay que aceptarlo como mandas. (Timeo $29 \mathrm{~b}-\mathrm{d})^{7}$.

${ }^{7}$ Ver nota 5. 
La filosofía — a pesar de su necesaria "no-verdad" no es una fantasía; es el método adecuado para conocer lo que no es más que la imagen de la verdad pura y simple. Por lo tanto, quedémonos con esta idea: la apariencia — que no es falsedad- es también necesaria para el conocimiento humano del mundo y de Dios; la filosofía — a pesar de su "no-verdad" y gracias a ellaconstituye un conocimiento auténtico: primero porque responde adecuadamente a la realidad - imagen de las ideas - y segundo, porque es expresión adecuada del hombre — otra imagen de una idea - y, por tanto, también de la única perspectiva que la hombre le es dado tomar para conocer todo también las cosa divinas (tà theia) — desde abajo, es decir, ayudado solamente por la luz natural de su razón. Lo cual no excluye una ciencia divina ni tampoco el conocimiento plenamente verdadero que Dios tiene de la "imagen del mundo" porque lo ve en la idea misma, es decir, en sí mismo.

En estas condiciones, ¿no tendrá Heidegger buena parte de razón al interpretar la imaginación trascendental como fundamento esencial del conocimiento ontológico? 
